\title{
Seismogenic Sources in the Lower Tagus Area Using Geophysical Data
}

\author{
C.C. Pinto* (LNEG), J.P. Carvalho (INETI), M. Costa (LNEG), T. Rabeh \\ (NRIAG), P. Terrinha (LNEG), H. Duarte (LNEG), J. Borges (CGE), B. Caldeira \\ $(\mathrm{CGE}) \&$ J. Cabral (LATTEX)
}

\section{SUMMARY}

The Lisbon and Lower Tagus Valley area have suffered the effect of historical earthquakes that caused important damages and loss of lives. Some of these earthquake sources are local but they are still poorly known due to the difficulty in finding geological outcrops, together with low-slip rates and erosion/ sedimentation processes that erase surface ruptures. Identification of seismogenic sources capable of producing large earthquakes from low magnitude instrumental seismicity has also proved unreliable in other areas of the world. Therefore, for a proper assessment of seismogenic sources for seismic hazard purposes we have used recently reprocessed and reinterpreted seismic reflection, potential-field data and overlaid relocated epicentres. Here we present a revised structural interpretation of the area based on seismic data and a basement map produced by magnetic modelling, 2D Euler deconvolution and trend analysis. This basement map, which greatly enlarges the seismic coverage of the study area, has shown new insights into deep-seated structures of the Lower Tagus Valley area and their relationship with seismicity. The information from fault parameters collected in this work will also help to locate the sources of historical events such as the 1909 Benavente earthquake using finite-element strong-motion simulation and comparison with observed seismic intensities. 


\section{Introduction}

The Lisbon and Lower Tagus Valley area (Figure. 1) has suffered the effect of moderate local earthquakes throughout its history, such as in 1344, 1531, 1909 that caused important damage (Moreira, 1985). Local seismicity has been recently considered of great importance (Vilanova and Fonseca, 2004; Peláez et al., 2002). However, instrumental seismicity and known geological faults

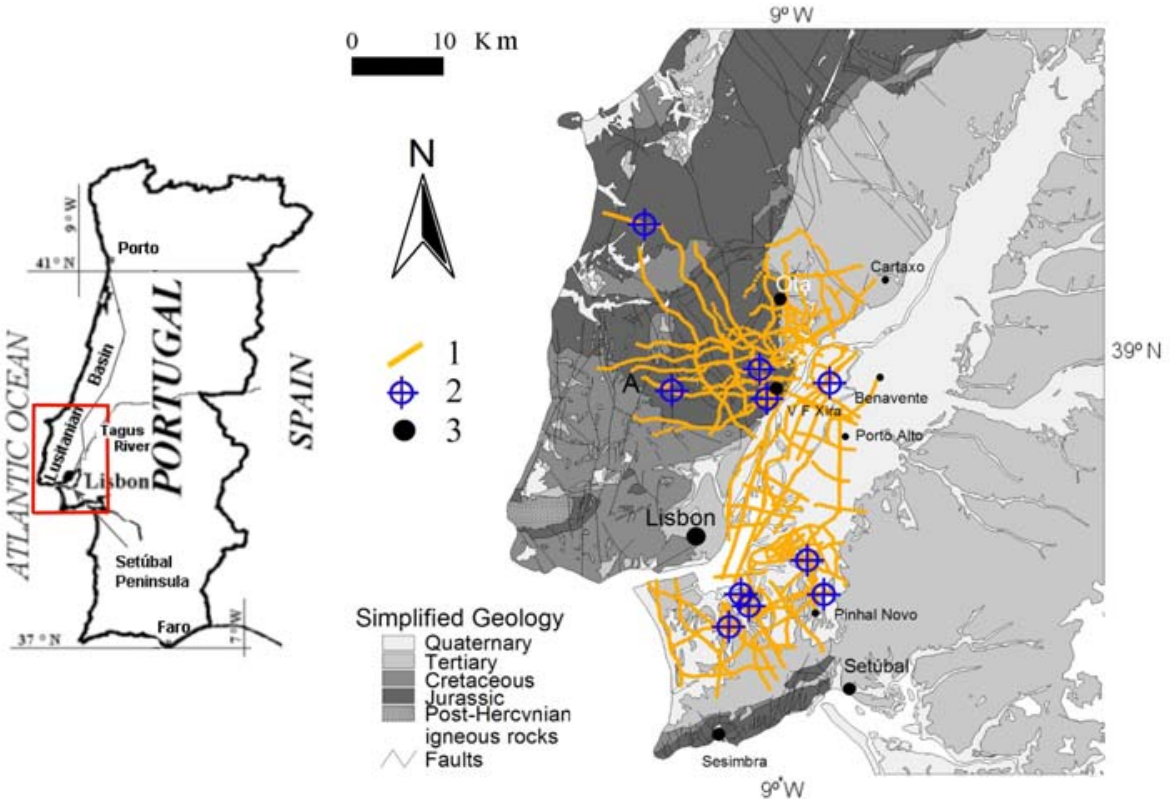

Figure 1 Location map and simplified geology of the study area (after Oliveira et al., 1992). 1-oil-industry seismic reflection profiles used for structural mapping of the basin; 2- deep wells; 3-localities. match poorly and the sources of local historical earthquakes are still under debate (e.g. Stich et al., 2005). The lack of geological outcrops, together with low-slip rates and erosion/sedimentation processes that erase surface ruptures contribute to this difficulty. Our goal is to identify and characterise the local onshore seismogenic sources using geophysical data for seismic hazard purposes.

The neotectonic activity in the mainland Portugal is characterized by vertical crustal movements and reactivation of preexistent faults of different tectonic styles under a compressive regime. Average slip rates are usually $<0.2 \mathrm{~mm} / \mathrm{yr}$, corresponding predominately to a low degree of activity (Cabral and Ribeiro, 1988; Carvalho et al., 2006). As a consequence of this tectonic setting, mainland Portugal experiences a low to moderate seismicity characterized by small events $(M<5.0)$ and offshore plate boundary generated occasional moderate to very large earthquakes, like the well known 1755 'Lisbon earthquake’.

Using the integrated interpretation of seismic reflection, potential-field, seismicity and geological data data, several non-outcropping fault zones have been recognized and tentatively mapped in the study area (Cabral et al., 2003; Carvalho et al., 2006; 2008). For some of them, such as the Pinhal Novo and Azambuja faults, there are evidences of tectonic activity since the Pliocene (Cabral et al., 2003; 2004). According with high-resolution geophysical data other structures were very probably active in the Quaternary, such as the Ota-V. F. Xira-Lisbon-Sesimbra fault (OVLS) or the Porto Alto faults (Carvalho et al., 2006; 2008). In this work, we present a revised interpretation of the seismic reflection data complemented with a structural map of the basement obtained from magnetic interpretation calibrated with well and seismic data in order to improve our knowledge of the major geological structures of the study area

\section{Methodology}

Several thousands kilometres of seismic reflection profiles have been acquired from the oil industry in the study area from the midst 1950's untill 1981. Studies of part of these data have been realised with paper migrated stacked sections (e.g. Rasmussen, 1998; Cabral et al., 2003). The data have been reprocessed by different companies and by the authors. Interpretation of two thousand kilometres of 

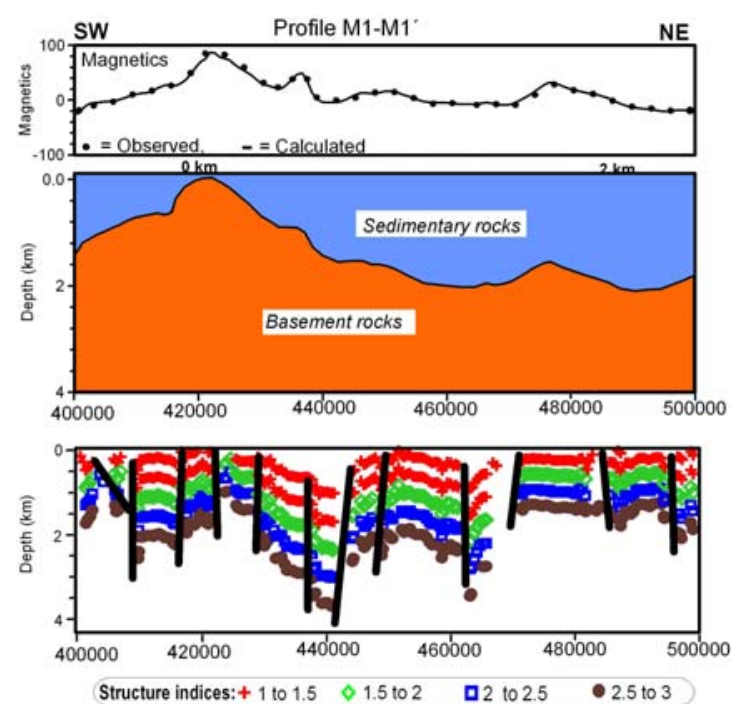

Figure 2 Top: Example of magnetic profile from a grid of profiles used to produce the basement map of fig. 4. Top: observed and calculated magnetic field; Middle: model obtained. Bottom: 2D Euler deconvolution solutions, with falt interpretation overlaid. these profiles in digital format has been carried out (Carvalho et al., 2007; 2008). For this work, the original interpretation made using OpendTect and paper sections was revised using Seisworks and additional seismic profiles. Magnetic and gravimetric data was used to locate salt and igneous structures and picking the basement.

In order complement the seismic interpretation and to cover areas where this information does not exist, a basement map was obtained from the interpretation of aeromagnetic data. We used data from an aeromagnetic survey (Fairey Surveys) acquired for the oil-industry in 1969 which was reprocessed for this purpose. A more recent IGRF model was extracted, data was reduced to the pole and a grid of profiles was established in order to sample the derived magnetic anomalies appropriately. The interpretation included gradient analysis, 2D Euler deconvolution and 2.5D magnetic modelling. The latter was calibrated using well, seismic and outcrop geological information. The relief of the

basement (paleoozic metamorphic and igneous rocks) was obtained form modelling and faults location was established using this information, 2D Euler solutions and the peaks of the horizontal gradient of the magnetic field.

In figure 2 we can see an example of magnetic interpretation made on one of the magnetic profiles. Finally, to identify potential seismogenic structures, relocated seismicity for the period 1970-2000 after Carrilho et al. (2004) was overlaid to the magnetic and seismic interpretations. Average error in the epicentral solutions is of $5 \mathrm{~km}$ which prevents the association with a specific fault but allows correlation with fault zones above a certain length (Carvalho et al., 2008).

\section{Results and discussion}

From the interpretation of the seismic reflection profiles complemented with the interpretation of magnetic and gravity data, we identified several important faults with seismogenic potential. This fault map is presented in figure 3.The identified faults affect an intra-Neogene horizon, close to the top of Upper Miocene. According to several authors (João Cabral, personal communication), the faults that affect this horizon have remained active into the Quaternary. Due to the inability to see

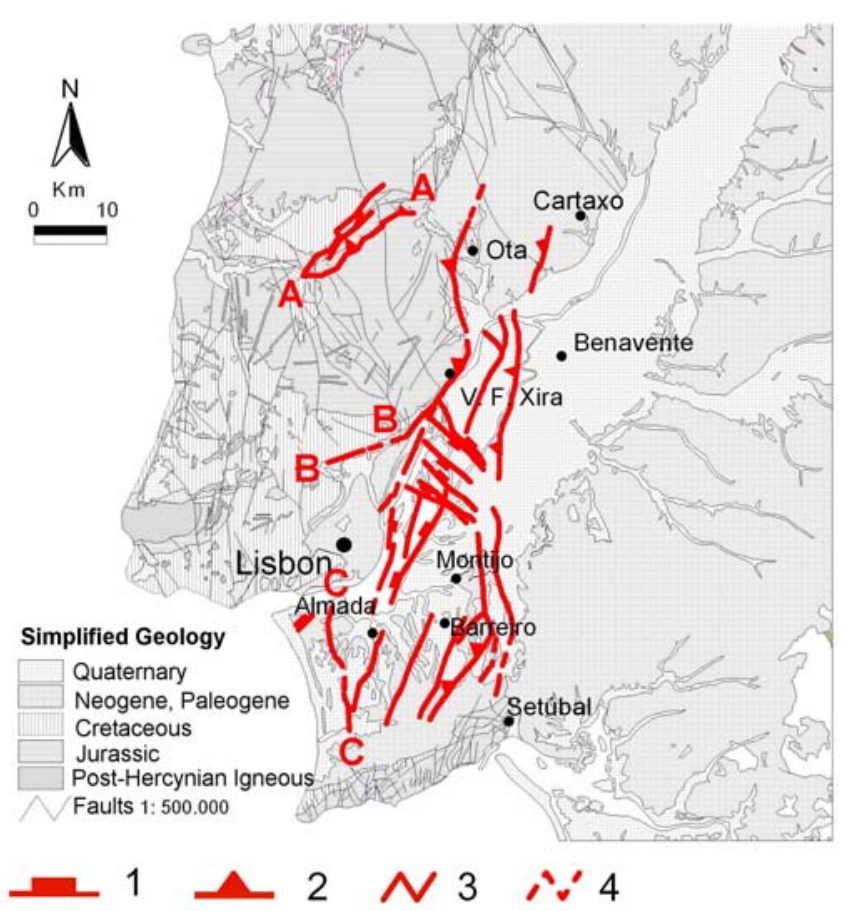

Figure 3 Map showing potential seismogenic structures affecting the Upper Miocene and Mesozoic (faults A, B and $C)$, after seismic reflection interpretation complemented with potential field data. 1- Normal fault; 2- Thrust fault; 3Unknown geometry fault, probably strike-slip fault; 4Probable fault, interpreted using potential field data. 


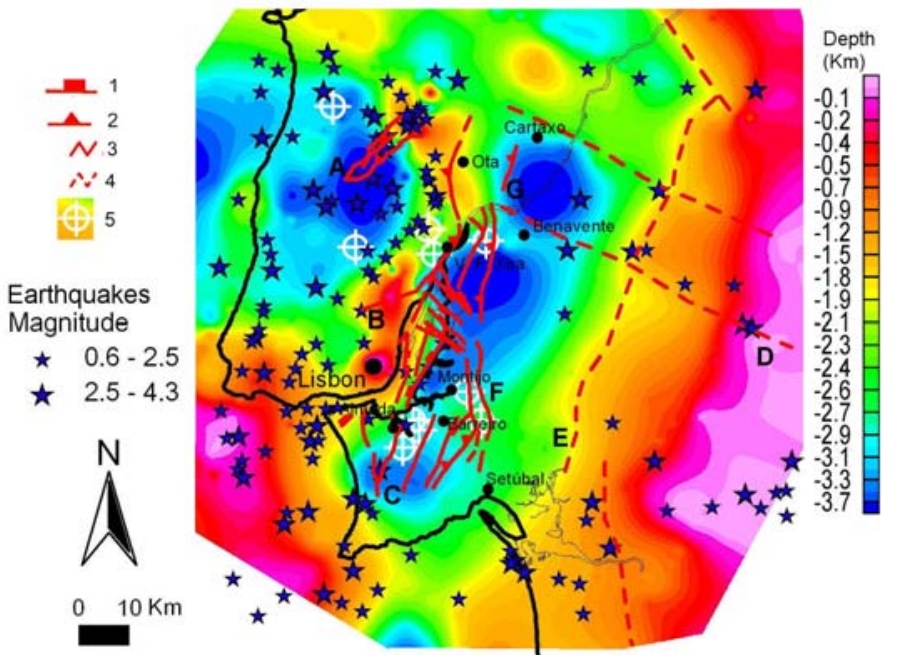

Figure 4 Basement Map obtained form calibrated magnetic modelling overlaid with seismicity and potential seismogenic structures obtained from seismic and potential-field data. 1Normal fault; 2- Thrust fault; 3- Unknown geometry fault, probably strike-slip fault; 4- Probable fault, interpreted using notential field data: 5- deen wells. correctly the shallow surface (including the Quaternary) with the geometry and acquisition parameters of the seismic profiles from the oil industry, high-resolution geophysical data needs to be acquired to confirm activity into the Quaternary.

In the presented map were also included some faults that affect only the Mesozoic: fault zone A because it shows a good correlation with seismicity; fault B was inferred from two seismic profiles and potentialfield data and was included in the map because it is very likely a segment of the OVLS fault zone which accordingly to recently acquired shallow high-resolution seismic reflection data is very probably an active structure (Carvalho et al., 2009) and fault C, for which the seismic profiles suggest a disruption at the scale of seismic resolution in the Cenozoic sediments.

In some cases it has not been possible to determine the fault geometry and kinematics, and in other cases the latter are inferred from indirect evidence by examining the type and width of deformation from the seismic profiles and /or using surface geological data.

The basement map shown in figure 4 extended the seismic coverage to the entire study zone and allowed new insights into deep-seated structures of the Lower Tagus Valley area. In spite of the nonunicity inherent to magnetic inversion/modelling methods, the produced map shows several wellknown geological structures from seismic reflection and well data such as the Arruda sub-basin, the Ota horst or the Samora horst. This give us confidence to the interpretation carried out from this map were there was no seismic or other sort of data.

We have tried to associate relocated epicentres to the fault zones obtained in this work. As already recognised in previous work, the OVLS fault zone controls the seismicity distribution in the area (Carvalho et al., 2007; 2008), in agreement with expected deformation of the upthrust block of the large crustal thrust fault that constitutes the western limit of the Lower Tagus Valley foreland basin (Carvalho et al., 2007). A few other fault zones present a clear relationship with seismicity, such as the Montejunto Thrust (fault zone A, in figure 4), fault D and fault E. Other faults which according to geological outcrop data have been active in Plio-Quaternary times (Cabral et al., 2003; 2004), the Pinhal Novo-Setúbal (falt F) and Azambuja faults (fault G), show no associated seismicity. In the case of the former structure, the presence of salt intruding the fault zone as observed in the seismic reflection data may be producing aseismic ductile deformation but in the latter case, low-slip rates and the short span of the seismic catalogue (30 years) may explain the discrepancy.

\section{Conclusions}

Using seismic reflection data and potential-field data we have been able to map hidden potential seismogenic faults. Some of these faults were previously unknown. Part of the detected structures presents a relationship with instrumental seismicity but other, which according to geological or geophysical data have been active in Plio-Quaternary times, are not no seismogenic or their slip-rates are too low to produce seismicity in the time span covered by the seismic catalogue. Also, in other 
areas of the world, instrumental seismicity is often located in different areas of large magnitude historical earthquakes. Therefore, to determine if the structures have been active into the Quaternary, high-resolution geophysical and geological studies are required. These studies were already performed over the Vila Franca de Xira (Carvalho et al., 2006; 2008) and Porto Alto (branch of the Pinhal Novo-Setúbal fault, Carvalho et al., 2006), and results suggest that both structures are active. Using the information from fault parameters collected in this work will also help to locate the sources of historical events such as the 1909 Benavente earthquake using finite-element strong-motion simulation (Grandin et al., 2007) and comparison with observed seismic intensities.

\section{Acknowledgements}

The authors thank the Portuguese Foundation for Science and Technology for funding projects SISMOTECTO-POCTI/CTE-GIN/58250/2004 and LISMOT/Strong Ground Motion in the Lower Tagus Valley-PTDC/CTE-GIN/82704/2006. We also acknowledge the Marine Geology Unit of LNEG for sharing a Seisworks licence.

\section{References}

Cabral, J., Ribeiro P., Figueiredo P., Pimentel N., Martins A., [2004]. The Azambuja fault: An active structure located in an intraplate basin with significant seismicity (Lower Tagus Valley, Portugal). Journal of Seismology, 8, pp. 347-362.

Cabral, J., Moniz, C., Ribeiro, P., Terrinha, P., Matias, L., [2003]. Analysis of seismic reflection data as a tool for the seismotectonic assessment of a low activity intraplate basin- the Lower Tagus Valley (Portugal). Journal of Seismology 7, 431-447.

Cabral, J., Ribeiro, A., [1988]. Carta Neotectónica de Portugal Continental (escala 1:1000.000), Geol. Surv. Portugal, Geology Dep. Fac. Science, Cabinet of Nuclear Safety and Protection.

Carvalho, J., Ghose, R., Pinto, J. Borges, [2009]. Characterization of a Concealed Fault Zone Using P and S-wave Seismic Reflection Data, extended abstracts of the EAGE Near Surface 2009, Dublin, A14, 5 pp.

Carvalho, J., Rabeh, T., Carrilho, F., Cabral, J., Miranda, M., [2008] Geophysical characterization of the Ota-Vila Franca de Xira-Lisbon-Sesimbra fault zone, Portugal. Geophysical Journal International.

Carvalho, J., Pinto, C., Costa, M., Rabeh, T., [2007]. Looking for earthquake sources in the Lisbon area, extended abstracts of the EAGE Near Surface 2007, Istanbul, P45, 5 pp.

Carvalho, J., Cabral, J., Gonçalves, R., Torres, L., Mendes-Victor, L., [2006]. Geophysical Methods Applied to Fault Characterization and Earthquake Potential Assessment in the Lower Tagus Valley, Portugal. Tectonophysics 418, 277-297.

Grandin, R., Borges, J. F., Bezzeghoud, M., Caldeira, B. and Carrilho, F., [2007]. Simulations of strong ground motion in SW Iberia for the 1969 February $28(\mathrm{MS}=8.0)$ and the 1755 November $1(\mathrm{M} \sim 8.5)$ earthquakes - II. Strong ground motion simulations, Geophysics. J. Int., Vol. 171, Issue 2, Pages 807-822, November 2007. doi:10.1111/j.1365- 246X.2007.0357.x.

Moreira, V.S., [1985]. Seismotectonics of Portugal and its adjacent area in the Atlantic. Tectonophysics 117, 85-96.

Oliveira, T. (coord.) et al., [1992]. Carta Geológica de Portugal, escala 1: 500.000. Serviços Geológicos de Portugal.

Peláez, J. A. M., Casado, C. L., Romero, J. H. [2002]. Deagregation in magnitude, distance, and azimuth in the South and West of the Iberia Peninsula. Bull. Seism. Soc. Am., 92, 6, 2177-2185.

Rasmussen, Erik S., Lomholt, S., Anderson, C., Vejbaek, O. V., [1998]. Aspects of the structural evolution of the Lusitanian Basin in Portugal and the shelf and slope area offshore Portugal. Tectonophysics 300, 199-225.

Ribeiro, A., Kullberg, M. C., Kullberg, J. C., Manupella, G., Phipps, S., [1990]. A review of Alpine tectonics in Portugal: Foreland detachment in basement and cover rocks. Tectonophysics 184, 357-366.

Vilanova, S. P., Fonseca, J. F. B. D, 2004. Seismic hazard impact of the Lower Tagus Valley Fault Zone (SW Iberia). Journal of Seismology, 8, 331-345.

Stich, D., Batlló, J., Macià, R., Teves-Costa, P., Morales, J., [2005]. Moment tensor inversion with singlecomponent historical seismograms: The 1909 Benavente (Portugal) and Lambesc (France) earthquakes. Geophys. Journal International 162, 850-858. 